\title{
Molecular Cardioprotective Effects of Curcumin
}

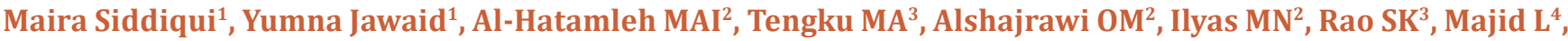 \\ Zubaidi $\mathrm{AB}^{2}$, Nordin Bin Simbak ${ }^{2}$ and Atif $\mathrm{AB}^{2 *}$ \\ ${ }^{1}$ Jinnah University for Women, Pakistan \\ ${ }^{2}$ Faculty of Medicine, Universiti Sultan Zainal Abidin, Malaysia \\ ${ }^{3}$ Institute for Community (Health) Development, Universiti Sultan ZainalAbidin, Malaysia \\ ${ }^{4}$ Department of Chemical Pathology, Pakistan \\ Submission: February 12, 2018; Published: March 14, 2018 \\ *Corresponding author: Atif Amin Baig, 2Faculty of Medicine, Universiti Sultan Zainal Abidin, Kuala Terengganu, Malaysia, Tel: +6096275646; \\ Email: atifameen01@gmail.com
}

Abstract

Curcumin is a polyphenolic compound of turmeric. It is considered best to use in our daily lives because of its therapeutic property and it adjusts multiple cell signaling pathways as well. Many types of research and clinical trials have proven the pharmacokinetics and effects of curcumin against several chronic diseases in human. Turmeric is used because of its multifunctional properties. One of its roles is played in medicinal sciences as it is used to treat the bacterial infection, inflammation, any digestive disorders and burns and it has also been used in many traditional spices in several countries especially in Asia. In our study, we mainly focused on the effects of curcumin on the cardiovascular system and atherosclerosis as diet has many roles in modulating the risk of development of several diseases.

\section{Introduction}

Curcumin is recognized as a strong anti-microbial agent which vigorously prevent from many chronic diseases like cancer, cardiovascular, diabetes, obesity and neurological and autoimmune diseases [1]. Turmeric (Curcuma Longta) is a wellknown herb which is cultivated in the southern and southwestern tropical area region. Turmeric is categorized in the ginger family. It is very popular in Iran, China, India, Malaysia, Polynesia and Thailand. It is frequently used in curry and soups etc due to its unique sensory properties [2]. Such comestible plants are of very significant because they are rich in phytochemicals which are non-nutritive chemical present in plants which take their active role to restrain macro chemical and anatomical process in the body of living organisms [3].

Curcumin (diferuloylmethane) is a major compound present in Turmeric (Curcumin longa) which is an Indian spice. Curcumin is known for its pharmacological activity [4]. The active compound present in curcumin is curcuminoid which is predominant phenol and provides identical bright yellow color to turmeric. The total concentration of curcuminoid present in curcumin is about $75 \%$ of total curcuminoids present in turmeric. $\mathrm{C}_{21} \mathrm{H}_{20} \mathrm{O}_{6}$ is the chemical formula of curcumin it has branched structure. Curcumin has tripartite functions, not only it is used as spice it is also used for its pigments and its medical purposes since a long period [5]. In research, it is mentioned that curcumin has a benefit to cure 560 unfavorable conditions [6].
Curcumin is used widely due to its property of fulfilling several functions at a time and it even doesn't have any side effect. It can benefit the consumer of all age group [7].

Curcumin is a well-known polyphenol which has an antiinflammatory, hypoglycemic, anti-thrombotic, antiproliferative, antioxidant, wound healing, and anti-microbial characteristics [8]. According to study which was carried since past quarter century, the pharmacokinetics, effectiveness and protective nature of curcumin's capability of curing diseases was determined [9].

\section{Multifaceted Barrier against Heart Diseases}

Curcumin is considered as a vital antioxidant that takes part in improving heart health. It maintains endothelial functions of the body with are directly related to cardiovascular diseases [10]. The endothelium produces some vasodilator and vasoconstrictor functions which help in maintaining the activity of anti-inflammatory cells. The endothelial vascopromoter function is directly linked to the long lasting effects of cardio vascular diseases. Some compounds in food can disturb the functioning of these vasco promoters such as Lipids usually lowdensity lipoprotein and cholesterol may interfere the functioning of vascopromoter by minimizing the bioavailability of nitric acid and also the trigger anti-inflammatory signalling pathways such as kappa [11]. 
Some recent studies show that curcumin may reduce the risk of complicated heart attack and strokes by preventing the development of atherosclerosis, or clogged arteries not only curcumin prevents heart diseases but it also helps in fighting against many other risk factors, including reducing chronic inflammation, suppressing the impact of high glucose and normalizing blood lipid profiles [12,13].

\section{Key to a good heart health}

Curcumin is an excellent compound that is suitable for the patients who have gone through the heart attack or heart surgeries because its impacts on the genes and help in quick recovery they take part in cardiac repair and proper cardiac functioning [14].

\section{Reduction in plaque buildup}

Turmeric is known for curing a wide range of heart-related disorders that occur due to plaque buildup and clot formation in the arteries of the heart because turmeric can avert clot formation and prevent plaque buildup. Usually, heart diseases occurred due to blood clots in the arteries while turmeric takes part to prevent this blockage and ultimately it lowers the risk of heart attacks $[7,14]$.

\section{Reduction in bad cholesterol}

Curcumin can also help in reducing the bad cholesterol as it prevents the clotting of blood platelets as it is the main culprit of heart diseases. It sends signals to the livers which enhance the production of messenger RNA $[7,12]$. The main goal of turmeric is to increase HDL level and decrease LDL level. The increased LDL level results in blockage of the arteries. Curcumin helps the liver to remove bad cholesterol so that the risk of heart attack can be minimized $[7,12]$.

\section{Preventing atrial/ventricular arrhythmias}

The provocative effects of curcumin have the possibility of preventing the atrial arrhythmias and it also plays a role to correct the pathway of $\mathrm{Ca}\left({ }^{2+}\right)$ homeostasis which can lead in the prevention of some ventricular arrhythmias that prevent chances of heart attack and stroke.

\section{Studies on Curcumin Profile}

In many studies, it is briefly discussed and found that curcumin shows an anti-cancer effect in living organisms mainly in animals and humans. It has been reported that curcumin suppresses the carcinogenic activity of abnormal cells that cause cancer in colon, breast, oesophagus, duodenums, oral cavity and liver as well as prostate.

Curcumin used in Asia for its many therapeutic effects on human health. In one study, protective effects of curcumin on cardio health were demonstrated. And it was suggested that it has a wide range of molecular targets including various healing effects such as its anti-inflammatory, anti-oxidant and anticarcinogenic [15].
Similarly, another study showed that $10 \mathrm{mg}$ of curcumin given twice a day for 28 days significantly lowered serum LDL levels and increased the serum HDL levels in patients with atherosclerosis.

\section{Curcumin \& Diabetic Cardiovascular Complications}

Diabetic cardiovascular or diabetic heart disease refers to a heart disease in a person who has diabetes. And here we have mentioned some complications of diabetic cardiovascular. In one study it was found that increased oxidative stress is linked to the pathogenesis of chronic diabetic complications. In another study, it was suggested that nitric oxide (NO) pathway plays role in generating free radicals.

Curcumin because of its remarkable anti-oxidant property has shown its effects on NO pathway oxidation in order to control the generation of free radicals. It seizes the reaction by which free radicals formed. And it is proved to be efficient in the development of cardiovascular complications in diabetes in a study.

\section{Curcumin \& atherosclerosis}

The medicinal property of curcumin in reducing the serum cholesterol level may protect against the pathological changes occurring with atherosclerosis. Atherosclerosis arises from various bodily processes that are characterized by either chronic inflammation, accumulation of lipids and vascular cells modifications in the arterial walls [16]. VSMC's (Vascular Smooth Muscle Cells) are the important cellular components of vascular media, and from a study, it came to know that its migration and proliferation lead to the formation of neointima (a thickened layer formed by migration of vascular cells) renders vessels particularly sensitive to atherosclerosis $[17,18]$. That's why VSMC's proliferation is the centre of attention to prevent the development of atherosclerosis. Curcumin has such potential to be effective in this case [19].

\section{Curcumin \& the cardiovascular system}

Curcumin decreases the severity of pathological changes and thus protects from damage caused by myocardial infarction. Curcumin improves $\mathrm{Ca} 2+$-transport and its slippage from the cardiac muscle sarcoplasmic reticulum, thereby raising the possibility of pharmacological interventions to correct the defective $\mathrm{Ca}^{2+}$ homeostasis in the cardiac muscle.

\section{Curcumin $\&$ its consequence on lipid metabolism}

Curcumin increases the alpha-tocopherol level and lowers the low-density lipoproteins and in vivo interaction between curcumin and tocopherol augments the bioavailability of vitamin E and reduces cholesterol levels. Curcumin binds with egg and soy-phosphatidylcholine, which in turn make a contractual with divalent metal ions to offer antioxidant activity.

\section{Conclusion}

The pharmacological properties and application of curcumin are now making progress very rapidly. According to one clinical 
study curcumin show its remarkable effects in almost all of the major organ systems of the human body. It also acts as an antioxidant by scavenging free radicals and giving a healthy life.

By the addition of curcumin to our daily life, we can get rid of several health disorders mainly heart which plays a vital role to maintain the body functions by supplying blood.

\section{References}

1. Kunnumakkara AB, Bordoloi D, Padmavathi G, Monisha J, Roy NK (2017) Curcumin, the golden nutraceutical: multitargeting for multiple chronic diseases. British journal of pharmacology 174(11): 13251348.

2. Kocaadam B, Şanlier N (2015) Curcumin, an active component of turmeric (Curcuma longa), and its effects on health. Critical Reviews in Food Science and Nutrition 57(13): 2889-2895.

3. Padhye S, Chavan D, Pandey S, Deshpande J, Swamy KV (2013) Therapeutic potential of curcumin, in medicinal chemistry. Acta Chimica Slovaca 6(1): 89-99.

4. Mandal A (2017) what is curcumin?

5. Curcumin for health. History of curcumin.

6. Barrett M (2012) Turmeric Naturally Fights Heart Attacks, Strengthens Heart.

7. http://www.inchem.org/documents/jecfa/jecmono/v52je04.htm

8. Wongcharoen W, Phrommintikul A (2009) The protective role of curcumin in cardiovascular diseases. International Journal of Cardiology 133: 145-151
9. Gupta S, Patchva S, Agarwal B (2013) Therapeutic Roles of Curcumin: Lessons Learned from Clinical Trials. The AAPS Journal 15(1): 195218.

10. Cartwright S (2017) Curcumin Provides Targeted Cardiovascular Protection.

11. Kinlay S, Lippy P (2001) Endothelial function and coronary artery diseases. PubMed 12(4): 383-389.

12. Miller K (2009) Curcumin May Prevent Clogged Arteries.

13. Martin M (2016) What is Turmeric and How to Use it to Prevent Heart Diseases?

14. Lal J (2012) Turmeric, Curcumin and Our Life: A Review. Bulletin of Environment, Pharmacology and Life Sciences 1(7): 11-17.

15. Goel A, Kunnumakkara AB, Aggarwal BB (2008) Curcumin as "Curcumin": from the kitchen to clinic. Biochem Pharmacol 75(4): 787-809.

16. Ross R (1999) Atherosclerosis-an inflammatory disease. N Engl J Med 340: 115-126.

17. Lusis AJ (2002) Atherosclerosis. Nature 407: 233-241.

18. Schwartz SM, Galis ZS, Rosenfeld ME, Falk E (2007) Plaque rupture in humans and mice. Arteriosclerosis Thrombosis and Vascular Biology 27: 705-713.

19. Pae HO, Jeong GS, Jeong SO, Kim HS, Kim SA, Kim YC, et al. (2007) Roles of heme oxygenase-1 in curcumin-induced growth inhibition in rat smooth muscle cells. Exp Mol Med 39: 267-277.

\begin{tabular}{l} 
Your next submission with Juniper Publishers \\
will reach you the below assets \\
- Quality Editorial service \\
- Swift Peer Review \\
- Reprints availability \\
- E-prints Service \\
- Manuscript Podcast for convenient understanding \\
- Global attainment for your research \\
- Manuscript accessibility in different formats \\
( Pdf, E-pub, Full Text, Audio) \\
- Unceasing customer service \\
Track the below URL for one-step submission \\
https://juniperpublishers.com/online-submission.php \\
\hline
\end{tabular}

